\title{
RATING OF OIL CIRCUIT BREAKERS
}

\author{
BY E. M. HEWLETT
}

\section{Abstract of Paper}

Paper points out several difficulties, which are encountered in the rating of actual circuit breakers, but generally favors that these ratings be on the basis of the current to be opened in the arc at the operating voltage of the system.

$\mathrm{T}^{\mathrm{H}}$

EE VARIABLE factors entering into the problem of rating oil circuit breakers make its solution very difficult.

Up to certain capacities it has been possible to determine definitely what oil circuit breakers will open. The experience of many years, during which oil circuit breakers grew from a few thousand volts for a few kilowatts station capacity, to 10,000 volts, 40,000 volts and higher voltages, for many thousand kilowatts station capacity, coupled with the facility of testing various designs under actual emergency conditions, has crystalized the requirements of circuit breakers of this kind and the constructive features of commercial design.

However, the capacity of stations is always growing, the forces dealt with are ever increasing, and consequently, new types of circuit breakers must be constantly developed, ratings of which cannot be based on actual past service. To test such circuit breakers systematically would be beyond the scope of any testing units at the disposal of any manufacturing company and would require the use of power stations of enormously high capacity.

The possibility of utilizing such power stations for the testing of circuit breakers is very limited, as in order to carry their connected load the big operating companies must generally have constant and instantaneous control of all their apparatus.

Thus, new designs of high-duty circuit breakers must, for the present, be rated mainly upon judgment based on past broad experience. For the engineer, the ideal way of rating circuit breakers is on the basis of the current which is actually opened 
in the arc at the operating voltage of the system, as in the present A. I. E. E. ruling. (This current in the arc is not the peak value of the short-circuit current curve, but is that value which prevails at the moment when the circuit breaker opens, at the point where it is installed.) However, in a rational design of circuit breaker, other factors must be considered besides current to be ruptured, primarily the power factor at the time of the event and the voltage regulation of the system. In the smaller capacities, these factors could be disregarded, as with them it has always been possible to allow very liberal safety factors without sacrificing reasonable proportions. We are therefore rating at the present time oil circuit breakers by arc current and system voltage up to certain capacities. As the capacities of the system and circuit breakers increase, as spacings and clearances become important design factors, and as materials employed in the construction of the circuit breakers must be used more nearly to their limits, it becomes necessary to take all conditions into account.

Oil circuit breakers for small stations and industrial service are often used by men who should not be called upon to figure the current and voltage values, which is necessary for selecting the proper type circuit breaker for their service.

For these conditions the kilowatt rating is most convenient, i.e. the total generating capacity of the system, or its equivalent, at the point of disturbance. Generally the kilowatt rating is based on the assumption, that the disturbance takes place so close to the generating apparatus, that reactance and resistance of connections between generating apparatus and the place of disturbance need not be considered. A certain initial reactance of the generating apparatus and a certain diminution factor of the current started by the disturbance, dependent on the time required by the circuit breaker to open the circuit after the disturbance has started, are assumed.

If the oil circuit breaker is located at some other point in the system with considerable line or transformer impedance between the generating apparatus and circuit breaker, allowance must be made for the current-limiting effect of this additional impedance. Instead of the generated kilowatt capacity, an equivalent kilowatt capacity must be used, which refers to the actual location of the circuit breaker in the system and is lower than generated kilowatt capacity, by an amount dependent on the characteristics of the intervening conductors and circuits. 
The physical dimensions of the conducting copper parts of the circuit breaker should always carefully be considered. Conducting parts must be of sufficient size to carry the rated current indefinitely without objectionable temperature rise, also be large and strong enough for the maximum current rushes between the instant of short circuit and the time of opening of the circuit.

The use of current-limiting reactors, or reactances in transformers and machines in connection with systems is increasing. The reactor may be in circuit permanently or only when the breaker is opening. Various means have been developed to insert reactors or resistance into the circuit as the circuit breaker opens. While such arrangements reduce the current which the circuit breaker opens, they cannot act quickly enough to reduce the instantaneous maximum current and the shock on the system which is the real point to be considered.

Finally, one man will require the ircuit breaker to open the most severe short circuits without the slightest indication of distress. Another man may be well pleased if the circuit breaker protects his more costly machinery, even if the circuit breaker itself is destroyed in doing so. Some one else may expect the circuit breaker to open two or possibly three times without requiring inspection or repair.

It is thus evident that there is a wide range of opinion as to what constitutes satisfactory operation; but as experience and information accumulates, this situation will gradually improve and we will approach closer to, and it is hoped will ultimately reach, the solution of the problem.

To sum up-I am in favor of rating circuit breakers on the basis of current in the arc and operating voltage of the system. The term "current in the arc" implies, that in defining its value all factors have been considered, which are necessary to determine the actual work to be performed at the time when, and at the place where, the current is interrupted.

I am not in favor of giving ratings to circuit breakers, in transient peak values which do not exist at the time of opening the circuit 


\section{Discussion on "Rupturing Capacities of Oil Circuit Breakers" (Hayes), and "Rating OF Oil Circuit Breakers" (Hewlett), Boston, Mass., December 8, 1916.}

Chester Lichtenberg: The standardization of the rating of the interrupting capacity of an oil circuit breaker is fast becoming an economic necessity. Manufacturing companies have a wide variety of product to offer but operating companies have difficulty in choosing suitable devices therefrom, because the duty which they will perform is not published in standard form. Consequently, the rating suggestions made by Messrs. Hayes and Hewlett are timely and should encourage engineers to submit their ideas on this important topic in order that their knowledge may be utilized in arriving at suitable standards.

It seems desirable to rate circuit breakers on the basis of the current in the circuit during the time the arc persists in the breaker. There is, however, some question regarding the value of this current. It is described by Mr. Hayes as "the maximum peak of the current wave that occurs while the breaker is opening." It is defined by Mr. Hewlett as "that value which prevails at the moment when the circuit breaker opens." Neither of these seems quite clear nor comprehensive and in place thereof, it is suggested that, "the average of the r.m.s. values of the current peaks on the transient side of the true zero line as measured by an oscillograph, during the time that the arc persists," be taken as the current interrupted by the breaker, when interpreting test results.

Another question in considering the interrupting capacity of an oil circuit breaker is the pressure voltage of the circuit. Mr. Hayes proposes to use "the r.m.s. of the open-circuit voltage that occurs immediately after the breaker opens." This suggestion has much to commend it but unfortunately if it is adopted it may further complicate the rating, on account of the pressure variations which systems may exhibit. Mr. Hayes has mentioned some of these. Besides, during ordinary switching conditions, the circuit pressure may rise momentarily to about three times normal, and under unusual conditions, it may rise as high as seven times normal just after the breaker clears the circuit. It is quite important, therefore, that if the breaker rating is to be separated from its application, a value of the pressure should be adopted which is independent of system characteristics.

The calculation of the interrupting capacity of a breaker at pressures other than those for which tests are available, presents a difficult problem. One rule states that any change in the operating pressure from the listed pressure ratings will usually change the $\mathrm{kv}-\mathrm{a}$. rating in about the same percentage. An example of this method is given by Mr. Hayes. The data have been rearranged in Table No. 1 and there has been added the maximum safe rupturing capacity of the breaker and the interrupting capacity of the breaker in amperes, both calculated as outlined in the Hayes paper. 
TABLE No. 1

\begin{tabular}{|c|c|c|c|c|}
\hline Rated pressure & $\begin{array}{c}\text { Operating } \\
\text { pressure }\end{array}$ & $\begin{array}{c}\text { Nominal } \\
\text { rupturing } \\
\text { capacity }\end{array}$ & $\begin{array}{c}\text { Maximum safe } \\
\text { rupturing } \\
\text { capacity }\end{array}$ & $\begin{array}{c}\text { Interrupt- } \\
\text { ing capacity at } \\
\text { operating pressure }\end{array}$ \\
\hline Volts & Volts & Kv-a. & Kv-a. & Amperes \\
\hline 22,000 & 22,000 & 10,000 & & \\
22,000 & 16,500 & 12,000 & 75,000 & 1,700 \\
22,000 & 13,200 & 13,000 & 81,250 & 2,600 \\
22,000 & 7,500 & 17,000 & 106,000 & 3,600 \\
22,000 & 4,500 & 19,000 & 118,750 & 8,200 \\
& & & & 15,000 \\
\hline
\end{tabular}

An examination of the last column of this table indicates that, while current ratings at 13,200 volts and above are logical, those at 7500 volts and 4500 volts seem too high. Here it is obvious that the formula only holds to about 50 per cent of the maximum pressure listed. Consequently, in adopting rating standards, it will be necessary to consider the limitations through which the formulas will apply.

In considering the interrupting capacity of an oil circuit breaker, it is necessary to remember the duty to be performed by the device. It is called upon to open an electrical circuit which at any given instant has a definite amount of energy stored in the medium surrounding it. The process of opening the circuit causes a change in the energy storage. Under the usual a-c. circuit conditions, a portion of the stored energy must be dissipated when the breaker is opened, the dissipation taking place partly in the breaker and partly in the resistance of the electrical circuit. Besides, account must be taken of the energy stored in the rotating parts of synchronous machines connected to the circuit, and the energy supplied by the prime movers during the circuit interruption.

The usual method of rating oil circuit breakers, as well as those proposed, take into account only the steady current conditions of the circuit. They usually consider its normal pressure or sometimes the pressure just after the circuit is opened, and the current flowing through the breaker. These factors, however, do not completely account for the energy to be dissipated by the breaker. It is, therefore, necessary, in addition, to consider the condition of the circuit immediately preceding an attempt to to open it and the power factor of the circuit during the attempt. In other words, any definition of the duty to be performed by an oil circuit breaker or the rating of its interrupting capacity should include a statement of the power factor on which the rating is based, the point of the current wave at which the arc is started, and other essential factors. The worst conditions of power factor and point of the current wave at which the arc is started should always be understood or defined. 
N. L. Pollard: In my opinion confusion will be avoided if all circuit breakers are given either a $\mathrm{kv}-\mathrm{a}$. or ampere-volt rating.

Mr. Hewlett stated that it might be necessary to rate a certain capacity of breaker, used a great deal in factories, in kilowatts, as this method of rating would be better understood by the users. If this is done, it may simplify matters for a certain class of users, but it certainly will complicate them for all others. Any purchaser knows the voltage of his system and what load in amperes he expects to carry, therefore he should have no difficulty in choosing the proper breaker. In case he is rot satisfied with his own judgment, he should get in touch with some engineer who is competent to advise him.

I have known of cases where the manufacturer of breakers was advised by the purchaser that his load was such that he never would have more than a certain generator capacity connected to his lines at any time, and the manufacturer recommended a breaker which in his opinion would be adapted for the service. Some time later additional generator capacity was installed and several of the breakers failed. Cases like this will always exist unless all users of breakers become competent engineers.

In regard to just what a breaker should do, the question has been raised as to whether it should rupture the circuit only once or several times, with or without putting itself out of commission. There are not many central station men who care to see their station walls and floor splashed with oil or have the switch disabled to the extent that it becomes necessary to put the feeder out of service while repairs to the switch are being made.

In trying to analyze the proper rupturing capacity of a breaker, we come back to the question as to what is meant by "distress". It might be considered to be in distress when a small quantity of oil is thrown out or the contacts are slightly burned. These indications would show that the limit of its capacity had about been reached.

The capacity of the breaker should be great enough to rupture the circuit at least three times without any appreciable quantity of oil being thrown out and without any damage to the switch.

George A. Burnham: The Standards Committee on Switching Equipment had hoped at this meeting to remove one of the apparent obstacles in our way, namely, that of determining a satisfactory method of rating the rupturing capacity of oil switches and circuit breakers.

From the manufacturer's standpoint, it is evident that we are really getting closer to a common basis or rating.

Both Mr. Hayes and Mr. Hewlett are, evidently, in accord as to the method of rating circuit breakers, and this method, if I interpret it correctly, is exactly in accord with the method of rating oil circuit breakers which I presented to the Institute at the mid-winter convention in 1913. 
The next important matter, it seems to me, is to select the proper terms to express the method. I do not, however, believe that it is for the best interests of all to include the word "arc" in the phrase which is to express the rupturing capacity of the switch or circuit breaker, for the reason that if we speak of the amperes at the arc it may lead one to believe that we are talking about the potential at the arc as well. Neither do I believe that we should speak of the voltage immediately after or during the time that circuit interruption takes place. For instance, suppose that we have a circuit breaker that is to interrupt a specific amount of current and that the working voltage of the circuit to which it is connected is 15,000 volts. Assume that at the instant the contacts part the voltage on the particular branch of the system which was short-circuited was caused to drop to 13,000 volts at the terminal of the circuit breaker. Now, how shall we rate the circuit breaker with reference to rupturing capacity, on 13,000 volts or on 15,000 volts? It is apparent that there is a possibility for a misunderstanding, which I do not believe should exist.

We all realize that the power factor as well as unsymmetrical current wave form, surges, etc., affect the rupturing capacity of the circuit breaker, but I do believe it would lead to needless confusion in bringing all these factors into consideration by attempting to express the duty of the circuit breaker under the average working condition.

It appears to me that the method of expressing rupturing capacity of a circuit breaker which is at the present time incorporated in the Standardization Rules is very clear and definite, in that it states amperes per phase at normal working voltage.

Mr. Hayes has very aptly put the question before us when he says it is a question of viewpoint. We know that at the present time we cannot say exactly what the switch will do under all possible conditions, but we can say that a circuit breaker is guaranteed to open, say, 6000 amperes at 2500 volts, based on actual test experience, and be assured that it will perform its function properly unless it is working under very special conditions.

There seems to be a difference of opinion as to what constitutes failure in an oil circuit breaker. I, personally, believe that a circuit breaker should be capable of going back into service after it has performed its function under its guaranteed limit. The question as to the number of times is worthy of consideration.

There is no reason but what more simple and direct terms may be used to express what we mean in reference to these matters, and the quicker we do away with the frills the quicker and easier will it be for us to get down to a more comprehensive basis, that we may all understand.

There is another matter which is, perhaps, trifling, but in working out the size of a breaker for a given system we usually arrive at the amount of current which the breaker is called upon 
to open under certain voltage conditions, and it would be very much easier to select the switch by consulting a table of the amperes per phase at normal working voltage which the various circuit breakers will satisfactorily open, than to attempt to select it from the ultimate $\mathrm{kv}-\mathrm{a}$. or bus-capacity basis.

John L. Harper: Our method of deciding on an oil switch at Niagara is to give the company that is used to building them a statement of our conditions, or get them to investigate for themselves; and then to install apparatus, that, when we put the plant back of it, will rupture properly under any duty put upon it.

However, there seems to be two classes of customers to consider - those who wish to get the switch that will just do the work and no more, and the other class, who are very desirous of getting a breaker that will always open and always be ready to go back into service, regardless of its cost and the possibility of having too large an instrument. Therefore, I would be in favor, in rating a circuit breaker, of using-referring to the illustration used by Mr. Burnham-15,000 volts as the maximum working pressure, and disregarding the lowering of the voltage at such time as the breaker may act, and in this way getting a breaker that will be sufficiently large to open under the very worst conditions, although possibly imposing a little upon the party who wishes to cut down the cost and the size of his breaker. I believe that that class of customers should be imposed upon by manufacturers, rather than those who desire and depend upon continuous and successful operation.

H. W. Buck: There was one point touched upon by $\mathrm{Mr}$. Burnham that I should like to amplify, and that is the question of what determines the successful operation of an oil switch. I, myself, have seen oil switches operate under all kinds of conditions, and I never have yet seen one fail to open the circuitbut they have done so at times at the expense of their own existence-and that is the question. Does the rating of an oil switch mean that it is going to open the circuit successfully at that rating, or does it mean that it can only open it with resulting destruction to itself? Between those two limits, there are all degrees of operation.

An oil switch, to successfully operate, within its rating should certainly be able to open a short circuit in such a way that it can immediately go back into service. If it is going to open the circuit and clear a short on the line, and at the same time blow up its tank and throw oil all over the station, that certainly should not be considered to come within its rating. I think that the successful opening of a circuit should be more clearly defined than it is at the present time.

John B. Taylor: There is at least a tendency to come to some kind of an agreement on this question of rating, since both of the authors want to deal in current and voltage, though there seems to be unnecessary confusion as to what particular current is to be taken, and what particular voltage is to be 
taken. The principal difference is that $\mathrm{Mr}$. Hayes wants to measure the voltage, not of the system before the trouble began, not of the system at some point while the trouble is on, but some final voltage which is not at all definitely defined. I hope that he will explain that a little more clearly. It is quite obvious from the oscillograph record exhibited, that there are a great many currents and a great many voltage values which may be picked off of the record between the time that the trouble begins and the time that the trouble is definitely over.

My own feeling on this question of rating is, that there is bound to be a great deal of difference of opinion and not much headway made, until the theory of the switch is discussed and a better agreement reached as to how the switch works. Now, while Mr. Hayes disclaims any intention of discussing the theory, scattered through the paper here and there, are various observations on how a switch is designed and the factors making one switch more effective than another. The reason why I feel that the theory of the switch is essential to progress, not anly on rating, but for developing switches for more extreme service, comes from reviewing the discussions that have been held on this oil switch matter in the Institute papers for the last 10 or 15 years. Two men will think they are discussing the same point, when they are not discussing the same thing at all. The design of the switch-the designers' working theory as to what factors make a switch effective - appears to be in a very hazy state. On the one hand, we have men talking about a vacuum close to the point of the arc, due to the fact that a solid body has been drawn out of the oil leaving a space which the oil must fill; and at the same time the same man will be showing records of pressure up to 50 or 100 pounds to the square inch.

As Mr. Hewlett has pointed out in his paper, the test of switches under extreme duty is almost impossible today. The expense, the trouble and the danger from interrupting the service on large working systems make the opportunity for those tests so few and far between, that the best that any designer can expect to get out of them is a line on the particular switch that he had there. If he has an opportunity to make several short circuits he may be able to see which one is the better, but such tests cannot be done day after day. The minor details of design, that make the difference between success and failure, cannot be fully tried out. Of course, the proof of the pudding is in the eating, and if a switch has been produced that does the work, it may be more or less immaterial whether the details are worked out to the best advantage. In view of the limited opportunities for doing this work, I feel strongly that there is need of designers and investigators stating their ideas of just how a switch behaves and what factors in the design of one switch make it work better than another switch. After there is some semblance of an agreement on these points, the question of rating will be easier. 
K. C. Randall: Some years ago transformers were built or designed by comparison, but they are now, built absolutely scientifically. That is, there is a limited amount of iron, a limited amount of copper, and a limited amount of insulation, which are necessary to the production of a certain performance. There is a mathematical calculation that takes care of it, and that is similarly true with induction motors, and more or less with other machinery. For circuit breakers, no such data are known. Circuit breakers are still comparatively built, and they are not designed on a technical basis.

We know how to build breakers that will perform a certain function; but it is possible, even probable, that the breakers that we are building today will be much more cumbersome, heavier, more expensive, than the breakers which we will build when we know something about breakers--I mean analytically. We know that an inductive circuit is more difficult to open than a like non-inductive circuit. But I don't know that any one will volunteer what the difference is? Whether a power factor of 60 per cent, 50 per cent or 10 per cent, bears a definite relation to the difficulty of the circuit-breaker problem. The technical analysis - the study - the real knowledge of the problem-has not been acquired at all.

Specifically, we don't know whether a tank that is 4 feet $(121.9 \mathrm{~cm}$.) deep, as against one that is 2 feet $(60.9 \mathrm{~cm}$.) deep, will handle twice as much current-will interrupt a circuit of twice the voltage - or will handle twice the $\mathrm{kv}$-a.; nor do we know whether the diameter of the tank-holding the depth the same-if doubled, will double the capacity of the rupturing ability. Now, if these conditions prevail-and I think those who are confronted with applying circuit breakers and designing them and building them agree - then we are not quite ready to finally say just what a rating of a circuit breaker shall be in terms of power factor, current and voltage.

It might be well, then, to suggest that for the time being we should stick to the one question. For a long time we have gone along with a very hit or miss, perhaps antagonistic, lot of local and almost individual methods of rating. If we should agree now to rate breakers by the current, as Mr. Burnham saidnot in the arc, but simply in the circuit; and the voltage of the circuit, the normal, operating potential-we will, I believe, obtain a practical working method which will be good for awhile, and will give an effective basis of comparison. Later on, when real knowledge of the problem has been acquired, we can, if desirable-and I frankly doubt whether it will be desirableintroduce the question of power factor.

It has already been said that probably the power factor, under the average condition of severe duty-say short circuitmay average fairly uniform; and if we build breakers which will deal with those fairly uniform conditions, we will solve the problem. 
Then comes a matter that has been touched on several times, which I call the "relation of freedom of distress to maximum rupturing ability or rating." A few of these points are: A function of safety; an indication of an available margin for additional duty; matter of appearance and orderliness; a source of security and confidence of the operators, where there is freedom from distress. Smoke and oil throwing are not necessarily proof of a near approach to the maximum rupturing capacity of the breaker; but, with all adjustments right, and with the operation as intended, such demonstrations should, at least, be rare.

Mr. Pollard, I believe, said that if you wanted to have an immaculate station-and I should think most operators would choose that, if it could be obtained at a reasonable expensea larger unit could be purchased, which would withstand the duty, and not make a demonstration which a smaller and cheaper unit would manifest. So that, after all, whether the unit shall go back into operation clean, unsoiled and noiseless, or whether it shall go back limping, or perhaps having sacrificed itself and really not go back at all, is a matter for the purchaser. The manufacturer is glad to build whatever the purchaser chooses to buy, usually; but, as Mr. Pollard said, it is up to the purchaser, who does the applying to decide what he wants. He can buy a small breaker and blow it up, or he can buy a large one and not blow it up.

The choice of breaker equipment for freedom from demonstration demands the same foresight into the future methods of operation from the operator as he looks forward to his growing loads, that is exercised when he purchases additional generating equipment.

H. W. Buck: For a common kilowatt rating and a common power house capacity back of the arc, the oil switch of course may have to meet the condition either of large current and low voltage, or small current and high voltage.

The plant at Niagara Falls is particularly well equipped to make this direct comparison, in that it has a large plant, operating at 2200 volts, and also another large plant feeding a high-tension line, with the same amount of power back of the short circuits, operating at 60,000 volts. I would like to ask of $\mathrm{Mr}$. Imlay, whether he considers rupturing the low voltage and large current more severe on oil switches than the same kilowatts output at high voltage on small current?

L. E. Imlay: We have very much less difficulty in rupturing the arcs on the high-voltage circuits than on the low voltage.

C. A. Adams: I should like to ask, then, why it is ordinarily considered that at the lower voltages the $\mathrm{kv}$-a. rupturing capacity is larger than at the high voltages?

E. M. Hewlett: In this particular case, Mr. Imlay is not comparing the same switches. He is comparing the small lowvoltage switch, which is insulated for a low voltage, with the large high-voltage switch which is insulated for a high voltage. 
The low-voltage switch is relatively smaller because it is not necessary to make it larger, the striking distance is not the limiting feature. Hence the high-voltage switch has a great deal more oil in it, is a larger device, and has a higher rupturing capacity.

S. Q. Hayes: I think there is one other point which might be brought out right here. At the higher voltage there is probably more reactance in the circuit, and the amount of power at the arc is probably somewhat less at the higher voltage than at the lower voltage.

H. R. Summerhayes: It seems to me, on that same point, that there is another thing that should be considered. On the high-voltage switch you are not limited in space, and not so strictly limited in investment, as the low-voltage switch. If the manufacturer were allowed to build a low-voltage switch, using the same space and the same investment as is used for the high-voltage switch, he could probably build a switch which would show a very favorable and remarkable performance. The design of the low-voltage switch has been based on investment considerations and space considerations. The low-voltage stations - the large low-voltage stations-at first were always located in large cities, where real estate was expensive and the switches had to be confined to the least space. A great many switches required a great many feeders out of the stations, so that space was a limiting factor. The high-tension switches, on the other hand, are generally, nowadays, put out of doors, and there is no such objection to the large quantities of oil as was encountered in the original designs of low-voltage switches.

Mr. Hayes speaks of rating the switch on the circuit voltage immediately after the short circuit. The question of the meaning of the word immediately comes in. Of course we understand that if the field of the generator is under the control of an automatic regulator which pushes up the field excitation as soon as a short circuit comes, then the voltage may rise to a very high point after the short circuit, but that takes time. I can understand that the current is going up, possibly, during the short circuit, but it seems to me that the voltage would not rise until after the switch had opened. On this very point it has been observed that what we might call a sustained short circuit is more difficult to open than one in which the voltage is not sustained.

I am in favor of rating switches on the current which the switch opens and the system voltage. One reason for that is, that nearly all devices used on constant potential systems are rated at the system voltage, and it would be very convenient for engineers to observe the same custom in rating switches, rather than to rate them on a voltage which may be different for every short circuit.

Mr. Hayes speaks of short circuits not occurring closer together than two minutes, the breaker being capable of opening the short circuit ten times within the course of an hour. It occurs 
to me that such an arbitrary rating would be rather difficult for an operating engineer to take care of in his system. That is, it would be rather difficult to design a railway system, or any other system, in such a way that short circuits would come no closer than two minutes apart. They are not under control.

The point that a switch should be guaranteed to open the circuit, and then be in condition to be re-closed, is one which is well taken. There is very little doubt that most operating engineers prefer to have the switch capable of being reclosed at least once. That, I think, should be a standard. As to the number of times, there may be a difference of opinion, and more investment may be required.

The rating in which the $\mathrm{kv}-\mathrm{a}$. capacity goes up in greater proportion than the voltage goes down, is rather difficult to understand, and is rather difficult to reconcile with the other statement in the paper, that the rupturing capacity is a function of the tank dimensions.

There is another point that might be raised, and that is, that different designs of circuit breakers may require different formulas to be applied for the difference in rupturing capacity when the voltage is varied. I think some of them would act differently, on that point.

P. M. Lincoln: It seems to me that the main question under discussion here might be almost called one of the proper selection of a name by which to call our circuit breakers. At the present time, and during the past, if we wanted, for instance, to get a circuit breaker for a 1000-kw. machine, we took its ampere capacity from that of the machine and then selected our breaker on the basis of the short-circuit ampere capacity. Thus for various conditions we had to select various breakers, depending upon the conditions under which they were to be used.

A $1000-\mathrm{kw}$. machine, if built upon the old specifications when regulation was the thing which was desired in generators above everything else, might be capable of giving 15,20,30 times or perhaps even a higher percentage, of its normal current upon short circuit. Under modern conditions, however, particularly since the practise has arisen of using reactances, in series with generators, instead of giving 20,30 or may be 40 times normal current, the modern generator may only give five to ten times normal full-load current on short circuits; so that, that condition introduces a decided factor in the selection of the breaker.

The question, therefore, is, in the future shall we select our breakers in regard to the normal current which they have to carry, or shall we select the breaker with regard to the maximum overloading-the worst condition that it must carry? I quite agree with both authors. Both authors take the position that the breaker should be selected, and it should be given a name with respect to the maximum short circuit that it has to interrupt. I quite agree with that view.

Some exception has been taken to the language of Mr. Hayes, 
when he speaks of the voltage to be interrupted. He calls the voltage that which exists immediately after the short circuit has been interrupted. I think $\mathrm{Mr}$. Hayes used that language to give a picture of what the breaker has to do during the process rather than with a view of determining the voltage of the rating. I believe that the proper voltage to be used in getting at this rating is the normal voltage of the circuit.

It seems, therefore, that the main question that we have under discussion in this session is the proper name to apply to breakers, and I quite agree with both of these authors, in feeling that the proper name to give to them is the final rupturing capacity, rather than the normal-ampere carrying capacity. Of course the breakers must have that normal ampere carrying capacitythat goes without saying. But the name to call them by should be their maximum rupturing capacity, rather than their normal ampere carrying capacity.

L. W. Chubb: The electromagnetic energy stored in a system when the breaker opens has to be dissipated either as heat in the breaker arc or stored as an electrostatic charge in the system, to be subsequently dissipated by oscillation and absorption in resistance. There are several different things to consider in the breaking of a circuit. The energy put in the breaker tank is a function of the power factor, the time of operation and the phase of the current at the first of the separation. If the breaker opens quickly at the zero point of current the breaker has no work to do and the energy will all go to increasing the voltage of the system. If the breaker takes a long time to open, the stored energy of the system and more coming from the generating station will be dissipated in the arc of the breaker. So that the time and speed of operation, the power factor, the ratio of line capacitance to inductance, and the kind of inductance are all things to be considered. It makes a difference whether the interruption and short circuit are at the far end of the line or near the station. A breaker in the station should handle a short circuit near the station, in which case there is the greatest current, lowest power factor, and lowest ratio of capacitance to inductance. With this low ratio of capacitance there is not the advantage of line elasticity, no place to store the energy, there is an almost instantaneous rise of voltage each time the current pauses at the zero point, which lights the arc repeatedly and the dynamic and stored energy must be taken care of in the arc under oil until the final break. Therefore it seems that to take care of the worst conditions, the rating of breakers should assume a zero power factor.

C. A. Adams: My interest in this subject is largely from the standpoint of standardization, to the end that the rating of an oil switch or circuit breaker may be definite, clear cut and determinable. In the early days of dynamo machinery, the maker's rating frequently differed from what we now understand as the continuous rating, by as much as 50 per cent. (usually in excess), 
due partly to crudeness in methods of design and calculation, partly to lack of digested experience, partly to lack of knowledge of the qualities of the materials employed, partly to the differing factors of safety employed by the various manufacturers, and partly to the differing allowances which the manufacturers made for the crudeness of the customer's estimate of the capacity required.

We are now in a somewhat similar stage of evolution as regards the rating of oil circuit breakers. The customer does not know exactly the work which the breaker will be called upon to do; the designer does not know how to design, with any reasonable degree of accuracy, a breaker to do just the work specified; and finally the manufacturer cannot easily reproduce the specified conditions of operation, to test his product.

Thus the task before us is two-fold: First, to reduce our knowledge of this whole subject to a more definite, computable and testable basis; and second, to agree upon certain definitions as to rating, etc., so that we will be talking the same language, so that both specifications and bids will be rational and comparable.

Out of the present discussion, one conclusion stands forth clearly in my mind, namely that the rating of an oil circuit breaker should be defined in terms of the work it can safely do, without reference to the nature or capacity of the system to which it may be connected by a particular customer. It is for the customer or his engineer to say what work it will be called upon to do, or to choose a standard breaker with a sufficient margin to cover his maximum requirement. If he wishes an unusually large factor of safety it is for him to specify the correspondingly larger standard rating, as he is the one to pay for this extra insurance.

Finally the task under discussion is not a small or unimportant one, and anyone who contributes even in part to its satisfactory completion deserves a large share of credit and appreciation from the profession at large.

S. Q. Hayes: Referring to Mr. Lichtenberg's discussion. My paper, as stated, is largely a series of disconnected notes. It really does not lay much claim to clearness of definition as to the proper method of this rating. I think probably the fourth line of the summary gives the gist of my idea in preparing this paper - that the main object was to open up a discussion; and I think we have opened up a pretty fair discussion on it. Mr. Lichtenberg I believe also brought out the question about the rating of the circuit breaker and the formula from which that is derived. That, as stated in the paper, is the rating assigned to it by the maker or the designer of that particular breaker. The makers have felt that the breaker which really has the 22,000volt insulation, and the oil and the tanks suitable for that service, will actually open 1700 amperes at 22,000 volts, and will be reoperative after opening such a short circuit. They also claim that that same breaker will actually open 15,000 amperes at 
4500 volts, and be immediately reoperative. They have made tests that prove that that particular breaker can fulfill that particular line of ratings. Whether that formula holds true for every particular line of breaker-as Mr. Summerhayes brings out-is another question. But the makers will guarantee that this particular breaker will meet the particular conditions stated.

Mr. Pollard and others brought out the question of rating in $\mathrm{kv}-\mathrm{a}$. or amperes and volts, and the question of the voltage immediately after opening the arc. Under normal conditions we actually rate a breaker at the service voltage. I wanted to point out the fact, however, that under the abnormal conditions met in certain cases, where you do have a very large rise in voltage, that the $\mathrm{kv}$-a. rating should be based on the voltage that is practically available for maintaining that arc, namely, the voltage that exists just after the breaker has cleared the circuit.

H. R. Summerhayes: Don't you think it would be better, as a basis of rating, to use the system voltage?

S. Q. Hayes. I think, as a basis for rating, that the system voltage is probably the best way of doing it. This paper of mine is not any attempt to force this method of rating; but my idea was to put up a method of rating, largely as a target, so as to get the ideas of various people on this subject.

I notice that Mr. Pollard agrees with the recommendation, that the manufacturer should give the rating which he assigns to his oil circuit breaker, and the user should decide whether that breaker actually is satisfactory for his conditions.

The question of distress that Mr. Pollard brought out, really is a question for the operating engineers to settle, rather than for the designer to settle.

As Mr. Adams indicated, one thing necessary is to select the proper terms to be used in rating circuit breakers and the proper method of determining whether the circuit breakers have met their guarantees or not. This paper of mine suggests certain terms, not as being the best possible terms to describe what is intended, but as one method of describing them, in order, to give others a chance to suggest better means of expressing what I have attempted to express in this paper.

Now, that point about whether the breaker should be rated at 15,000 volts or 13,000 volts is, to a certain extent, answered by the recommendation of using the voltage that will exist immediately after the breaker has opened the circuit. That very difficulty is indicated on the curve. After opening, the circuit will undoubtedly have gone back to 15,000 volts, and may be a trifle higher.

Mr. Harper brought out the point that the practise of his company is practically to have the manufacturer send an engineer to investigate the particular conditions and then recommend a breaker that will meet those particular conditions. Now, in plants of the size of Mr. Harper's, that can usually be done; but the idea of this paper was to practically settle on a 
basis of rating that would take care of probably 90 per cent of the cases. There are undoubtedly other cases-maybe 10 per cent of the whole - where the operator will largely have to depend on the designing engineer- the manufacturing engineerguaranteeing that he will actually furnish a breaker to meet the particular conditions.

Mr. Harper very aptly brought out the facts that there are two classes of customers. In making a note on Mr. Harper's statement, I called these people "minimum and maximum customers"- one who will be satisfied with the minimum, namely, the cheapest breaker, that will just get away with his service; and, the other one, who wants the best that can be purchased, irrespective of price. Now, naturally the manufacturer would like to see more of that latter class.

Mr. Buck brought out the point of what really was a successful operation; and various other people agreed with Mr. Buck that it was necessary to have repeat operation.

Now, on that oscillogram (referred to by Mr. Taylor), the point that I would take as to the maximum voltage just after opening is the point which is marked on the oscillogram "short circuit opened." You will notice that on this particular system, where this test was made, that point is just slightly above the normal station voltage.

Mr. Taylor brought out the point that testing under actual conditions is almost impossible. As a general rule, that statement is entirely correct. There are a certain number of tests that have been made on plants of comparatively large capacity, so that the operators know, or can know, that the manufacturers really have some actual data on which their apparatus is based.

Mr. Randall brought out the point that circuit breakers are what he called "comparatively built," and "comparatively designed," and that no real analysis has been made of a circuitbreaker design, and that no actual data have been obtained as to the effect of changes in dimensions. Now, those statements are entirely correct. No definite data have been secured as to the effect of increase in dimensions; but a certain amount of comparative data have been available. It is known that a certain type of breaker, with a tank of a certain diameter, will do a certain amount of work, and that the same general design of breaker, with a larger tank, will open a greater amount of power.

Mr. Randall also agreed with the statement made by various speakers, that the current of the circuit to be opened really should be the current at the normal voltage, and not the current that would exist after opening the arc. And he also brought out the various features that would occur at the time of rupture, which he spoke of as "demonstrations."

Mr. Imlay stated that he has found there is less difficulty opening a certain station capacity at 60,000 volts than at 2200 volts. In answering that point at that time I practically asked Mr. Imlay another question, and that was whether at 60,000 
volts there really was not more reactance in his circuit, so that the power at the arc really was less on the 60,000 than on the 2200 -volt circuit. Now, Mr. Summerhayes and Mr. Hewlett practically brought out, in answer to Mr. Imlay's point, that for the higher voltage, space and price were minor considerations. So that it is undoubtedly true that the high-voltage breakers, which Mr. Imlay has in his plant, open their circuits with less fuss than the low-voltage breaker.

Mr. Imlay I believe also brought out the question of the rating of the low-voltage breaker-the rating of a breaker being given greater for low voltage than for high voltage. I answered that question earlier, to the effect that those are the ratings which the manufacturer of that breaker guarantees the breaker will meet.

Mr. Summerhayes brought out the point that the space and the price of a low-voltage breaker, particularly when installed in city plants, where real estate was of vast importance, was one of the limiting features on the low-voltage breaker that was not met with in the high-voltage breaker; and that given more or less unlimited space and more or less unlimited price the low-voltage breaker could be made to open the circuit just as readily as the high-voltage breaker.

Mr. Summerhayes also stated that, it is his recommendation that the current rating should be on the system voltage. I practically agree with him; but I have brought out the point that for those particular conditions where we did have a high rise in voltage after an arc, that it will have to be watched rather carefully. Now, just on that point, there is one feature of circuit-breaker operation that some people lose sight of, and that is, that if you have a number of parallel connected circuits and one of them is opened due to a short circuit on that particular feeder, the duty is less on that breaker, because the system can discharge over the other circuits, than if that were the only circuit and it had to open all of the stored magnetic energy of the system.

Mr. Lincoln brought out the fact that the real feature was the proper selection of the name to be assigned to a circuit-breaker rating. And Mr. Lincoln stated correctly my viewpoint on that question of the open-circuit voltage that took place immediately after the breaker opened.

Mr. Chubb brought out the point of the energy to open and the storage of energy, and the point that I just made, about circuit breakers and parallel circuits, takes care of that point.

Mr. Adams felt that the rating of the breaker should be practically independent of the system; and, if it is possible to do so, I feel that that is the proper method of rating.

E. M. Hewlett: In reference to Mr. Pollard's point, and as Mr. Hayes stated, the manufacturer would like to have only one rating, and that rating for safety and service. Unfortunately, there are two classes of customers. Some want all they can 
get and others are content with just enough to squeeze through. You must consider both parties in the designing and the rating, so that you will need a rating that can be used both ways, or let a different safety factor be taken by the man who is willing to take the risk.

Mr. Randall is quite right in reference to our data. We have a great deal comparing different capacities and different dimensions, and the service that the switches have given will bear out the way we have used that data. I think that the manufacturers have selected ratings that have given on the average, very good service.

Mr. Lincoln spoke of using the rating-that is, the rupturing capacity rating--as the rating of the switch. I think, however, that a switch needs a first and a last name, as well as some other features, and that you have to give it not only a rupturing rating, but also a normal current carrying capacity at the station voltage.

Then, to take up the last point, the rupturing capacity should be stated in the actual current that the switch is called upon to open at the operating voltage. There are a great many factors, you can see, that have to be brought in; but we can use such a rating as this until such time as we find we have sufficient data to formulate a new rating.

P. Lindemann (by letter): It is quite evident that we will have as many types of circuit breakers as we have types of apparatus or systems to be protected.

Taking into consideration our present method of rating generators, transformers and motors, it seems most preferable that our oil switches or other protecting devices be treated with a like method of rating, so for a generator having a given name plate rating that a similar name plate rating be placed on the oil switch to signify the proper size of switch necessary.

By this method for a transmission line the proper oil switch would be one having a name plate rating equivalent to the current, voltage, frequency and power factor of the line which it is to protect.

Assuming the line connected to generator bus bars, a generator type of switch would be selected and if the switch was to be placed at the far end of the same line with no load taken off between them, the two oil switches should have the same ratings theoretically, their types however would be different.

It seems to me that the possible surges of voltage and current should not enter into its name plate rating, but rather that they be assumed in the design by the manufacturers.

In addition to the above an oil switch of such design as to take care of twelve interruptions of its maximum rating at two minute intervals before inspection is necessary, would be ideal practically. 